\title{
Source Terms for Plutonium Aerosolization from Nuclear Weapon Accidents
}

\author{
RECEIVED \\ OCT 061995 \\ Douglas R. Stephens \\ OSTI
}

\author{
D Division \\ Counterproliferation Group
}

July 1995

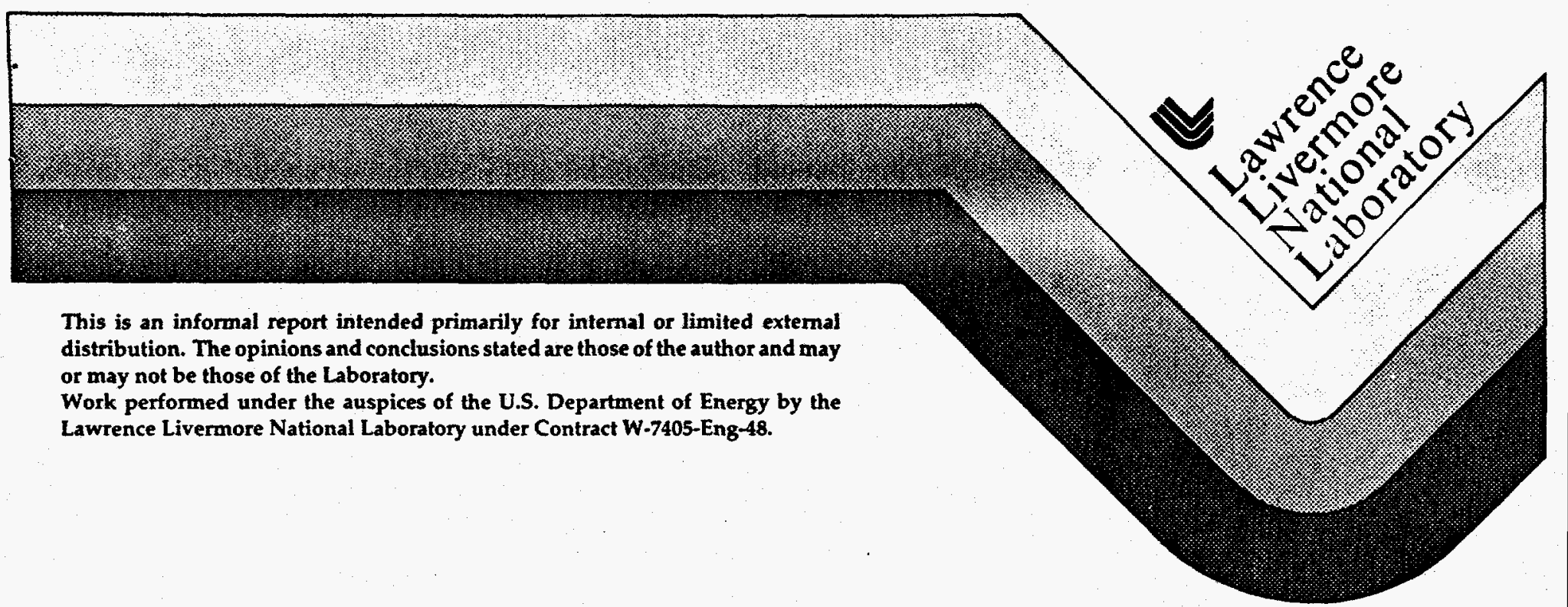

DISTRIBUTION OF THIS DOCUMENT IS UNLIWITEO
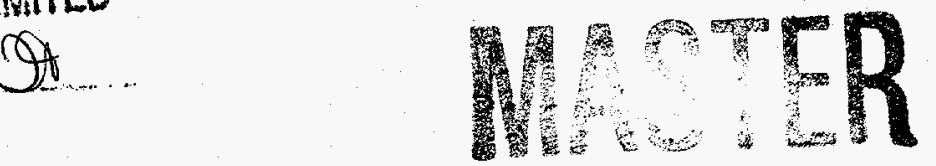


\section{DISCLAIMER}

This document was prepared as an account of work sponsored by an agency of the United States Government. Neither the United States Government nor the University of California nor any of their employees, makes any warranty, express or implied, or assumes any legal liability or responsibility for the accuracy, completeness, or usefulness of any information, apparatus, product, or process disclosed, or represents that its use would not infringe privately owned rights. Reference herein to any specific commercial products, process, or service by trade name, trademark, manufacturer, or otherwise, does not necessarily constitute or imply its endorsement, recommendation, or favoring by the United States Government or the University of California. The views and opinions of authors expressed herein do not necessarily state or reflect those of the United States Govemment or the University of California, and shall not be used for advertising or product endorsement purposes.

This report has been reproduced

$$
\begin{aligned}
& \text { Available to DOE and DOE contractors from the } \\
& \text { Office of Scientific and Technical Information }
\end{aligned}
$$
P.O. Box 62, Oak Ridge, TN 37831

Prices available from (615) 576-8401, FTS 626-8401

Available to the public from the National Technical Information Service

U.S. Department of Commerce 5285 Port Royal Rd.,

Springfield, VA 22161 


\section{DISCLAIMER}

\section{Portions of this document may be illegible in electronic image products. Images are produced from the best available original document.}


Source Terms for Plutonium Aerosolization from Nuclear Weapon Accidents

Douglas R. Stephens

January 5, 1995

\begin{abstract}
The source term literature was reviewed to estimate aerosolized and respirable release fractions for accidents involving plutonium in high-explosive (HE) detonation and in fuel fires. My estimates are:
\end{abstract}

HE detonation

Fuel fire

\begin{tabular}{|l|c|c|c|c|}
\multicolumn{2}{c}{ Aerosolized } & \multicolumn{1}{c}{ Respirable } & Aerosolized & \multicolumn{1}{c|}{ Respirable } \\
\hline $\begin{array}{l}\text { Lower } \\
\text { bound }\end{array}$ & $75 \%$ & $15 \%$ & $0.1 \%$ & $0.005 \%$ \\
\hline $\begin{array}{l}\text { Expected } \\
\text { value }\end{array}$ & $100 \%$ & $20 \%$ & $1 \%$ & $0.05 \%$ \\
\hline $\begin{array}{l}\text { Upper } \\
\text { bound }\end{array}$ & $100 \%$ & $30 \%$ & $10 \%$ & $0.5 \%$ \\
\hline
\end{tabular}

For HE detonation, all estimates are based on the total amount of Pu. For fuel fires, all estimates are based on the amount of Pu oxidized.

I based my estimates for HE detonation primarily upon the results from the Roller Coaster experiment, especially the Clean Slate I test.

For hydrocarbon fuel fire oxidation of plutonium, I based lower bound values on laboratory experiments which represent accident scenarios with very little turbulence and updraft of a fire. Expected values for aerosolization were obtained from the Vixen A field tests, which represent a realistic case for modest turbulence and updraft, and for respirable fractions from some laboratory experiments involving large samples of $\mathrm{Pu}$. Upper bound estimates for credible accidents are based on experiments involving combustion of molten plutonium droplets.

\title{
Introduction
}

In May of 1991 the DOE Pilot Safety Study Program established a group of experts to estimate the fractions of plutonium which would be aerosolized and respirable for certain nuclear weapon accident scenarios. The Study requested the information in the form of lower bound ( $10 \%$ confidence level), expected value and upper bound ( $90 \%$ confidence level. As one of the "experts" I re-examined the Pu source term 
literature in order to provide my input, which is included in the Pu aerosolization final report. ${ }^{1} \mathrm{My}$ findings are summarized in this report.

\section{Discussion}

In the following discussions, particle size is referenced to aerodynamic diameters, that of a spherical particle of unit density $\left(1.0 \mathrm{~g} / \mathrm{cm}^{3}\right)$, also referenced as equivalent diameters. Respirable particles are those of $10 \mu \mathrm{m}$ diameter or less. For $\mathrm{PuO}_{2}$ this corresponds to particles of $3 \mu \mathrm{m}$ or less. $\left(D_{a} \sim D_{0} r^{1 / 2}\right.$ where: $D_{a}=$ aerodynamic dia., $\mathrm{D}_{\mathrm{O}}=$ actual dia., $\mathrm{r}=$ density.]

\section{HE detonation}

Pu dispersion/experimental data from controlled one-point detonations of nuclear explosives were obtained from Operation Plumbob (1957) and Operation Roller Coaster (1963). The most valuable source term data were obtained from Roller Coaster.

Results from these experiments indicated that essentially all (100\%) of the plutonium was fragmented and comminuted into small particles and entrained in the detonation gases.2-3 Further reaction apparently takes place as the plutonium aerosol is dispersed, with the final result that the plutonium fraction of the aerosol is composed of plutonium dioxide. The most relevant mechanisms appear to be prompt vaporization and combustion, melting and liquid droplet disintegration and combustion, and shrapnel combustion.

Approximately $20 \%$ of these particles were small enough to be respirable, as is shown in Fig.1. 2 Respirable fractions varied from 16\% (Double Tracks, Clean Slate II and III) to $20 \%$ for Clean Slate I. ${ }^{3}$ The best data appeared to be obtained for Clean Slate I.

Field explosive dispersal studies with surrogate plutonium materials and laboratory experiments with plutonium have been carried out since 1974 at Sandia National Laboratories. 410 The effort, which has included modeling, has been carried out under the PAGE (plutonium aerosol generation experiments), PDSP (Plutonium Dispersal Studies Program) programs, and the NEST program. Results of the studies indicate that the amount of metal aerosolized is a function of the ratio of the HE to metal mass.

Luna and Hartman ${ }^{10}$ recommended, on the basis of the NEST-supported effort, that the innermost $20 \%$ of the pit (the mass of material contained within the HE) would be aerosolized, and of that, $20 \%$ would be respirable. These criteria are said to be consistent with the Roller Coaster data due to the design of the pits used in those 
tests. At this time the experiments and computations which support these conclusions have not been fully documented.

Recent hydrodynamic calculations by Goodwin 11 and by Clarke 12 appear to support an interpretation other than the simple aerosolization of the innermost $20 \%$ of the pit.

Therefore, until the recent results have been more thoroughly peer reviewed, I recommend using the published results from the Roller Coaster series for expected Pu source terms for HE detonation; i.e., $100 \%$ aerosolization and $20 \%$ respirable fraction, with the published particle size distribution as shown in Fig.1.

There is little data to generate lower or upper bounds for HE detonation. The following are tentatively suggested as SWAGs only, all based on the total amount of plutonium: involved in the accident.

Lower bound: $75 \%$ aerosolized, of which $20 \%$ is respirable. This SWAG is based upon recent hydrodynamic calculations. 11,12

Upper bound: $100 \%$ aerosolized, $30 \%$ respirable. This SWAG is based upon electromagnetic launcher experiments with molten uranium by Benson and Rader. ${ }^{9}$

\section{Deflagration-to detonation (DDT)}

This accident scenario is assumed to involve a conventional HE-containing weapon which is heated, the explosive begins to burn, pressure builds up from the evolved gases, which causes the burn rate to accelerate and to develop into a shock, resulting in detonation of the remaining $\mathrm{HE}$. Others have estimated that $85-95 \%$ of the $\mathrm{HE}$ would remain unburned prior to detonation.

Neither data nor calculations appear to be available for this scenario. So, for want of any substantive recommendation, the following tentative SWAG is suggested (based on the total amount of plutonium involved in the accident):

Expected value: $80 \%$ aerosolized, of which $20 \%$ is respirable Lower bound: $60 \%$ aerosolized, of which $20 \%$ is respirable Upper bound: $100 \%$ aerosolized, $20 \%$ respirable

Fuel Fire

The amounts of plutonium respirable or aerosolized resulting from a nuclear weapon accident involving fuel fires obviously depend upon details of the accident scenario. For example, if a weapon is in a fuel fire but the plutonium is at least partially contained, then even if the Pu is melted it may form a partially shielded, quiescent pool, the oxygen content of the contacting air may be depleted, and the resulting updraft may be minimal. In such a case the amount of aerosolized Pu would be very low. On the other hand, if the Pu is melted, then breaches the pit, falling for some distance through a hydrocarbon fire as a very thin stream, even 
dispersing as droplets, the amounts of respirable and aerosolized Pu would be very large. Clearly the amount of aerosolization depends upon mechanical effects and velocities as well as thermal effects in the fire. Thus, the upper and lower bounds of fuel fire aerosolization and respirable fractions will vary by a considerable amount. Defining release fractions over such a wide range of credible accident scenarios is a difficult task

There is no lack of experimental data for Pu release fractions in thermal experiments. The problem is that each Pu release experiment was conducted under conditions which may or may not reflect those of a credible accident for a nuclear weapon in a hydrocarbon fuel fire. Most of the data were taken under laboratory conditions more typical of a partially shielded, quiescent molten pool of Pu or oxidation of solid plutonium, in each case with little or no updraft. The Vixen A experiment is the only field test conducted under conditions which more realistically simulate an actual accident involving a plutonium-containing nuclear weapon exposed to a hydrocarbon fuel fire. In the following, various Pu thermal experiments will be critically examined in an attempt to establish credible Pu release bounds for weapon accidents in an actual fire.

The Vixen A trials, conducted in 1959 in Australia ${ }^{13}$ appear to simulate an actual burn situation much more closely than the laboratory experiments. In these experiments, 200 gram rods of plutonium ( $1.3 \mathrm{~cm}$ diameter $\times 7.6 \mathrm{~cm}$ long) were suspended in a stainless steel basket in a $4 \mathrm{ft}$. square $\times 11 \mathrm{ft}$. high chimney. A tray below the stainless steel basket served to collect oxide and other fragments. Two open-air-plutonium-burning experiments were performed to determine the fraction of oxide released and to determine the air and ground concentration downwind.

The chimney was instrumented with thermocouples and fueled with gasoline. The chimney fire was designed to produce a stable fire which would simulate a section of a large fire.

In the first plutonium experiment, the metal temperature reached $860^{\circ} \mathrm{C}$ in 10 minutes and remained at about this temperature for $\mathbf{2 3}$ minutes. The sample was found to be mostly metal with a hard oxide layer. Of the original $203 \mathrm{~g}$ of metal, $20 \%$ was oxidized. By material balance (see below) Stewart reports that about $1 \%$ of the metal sample was dispersed as an aerosol.

In the second plutonium experiment, the sample was slowly heated at $10^{\circ} \mathrm{C} /$ minute to $550^{\circ} \mathrm{C}$. At this point the sample ignited and reached $725^{\circ} \mathrm{C}$. Average temperatures were of the order of $600^{\circ} \mathrm{C}$. The sample was found to be almost completely converted to oxide, and an upper limit of $3 \%$ aerosolization was determined.

In ref. 13 Stewart discusses his interpretation of the release fractions, which I define as aerosolized (not necessarily respirable) and Stewart defines as "dispersed as oxide 
if combustion to loose oxide is complete." In his first experiment $0.2 \mathrm{~g}$ were dispersed, by integration of ground deposition (Table 13 of the Vixen report). But Stewart concludes (P. 25) that by comparison to the more complete second experiment, $0.3 \mathrm{~g}$ is a better value.

So the fraction aerosolized from the first experiment is interpreted as $0.3 \mathrm{~g}$ of a $203 \mathrm{~g}$ sample which was $20 \%$ oxidized in the experiment, or:

$$
F=0.3 /(0.2)(203)=0.74 \%
$$

The second sample which weighed $202 \mathrm{~g}$ was apparently completely oxidized, and by integration of ground deposition contours (Table 13 in the Vixen report) $1.7-1.9 \mathrm{~g}$ were aerosolized. Then:

$$
F=1.7-1.9 /(1.0)(202)=0.84-0.94 \%
$$

The average amount aerosolized from the two experiments is $0.84 \%$. Stewart recommends a release fraction of $1 \%$ and a respirable fraction of $0.05 \%$, although he measured $0.0035 \%$ based upon incomplete ground deposition data. In a later analysis of the Vixen data, Carter ${ }^{14}$ estimated that $2.2 \%$ was dispersed, although not necessarily aerosolized, as some of the particles were large.

In a recent re-analysis of the Vixen $A$ air sampler data, Luna ${ }^{15}$ estimates the respirable release fraction to have been .01 to $0.03 \%$.

Others ${ }^{16}$ have argued that the Vixen tests do not represent credible accident scenarios for fuel fires involving nuclear weapons and if used would lead to overestimates of aerosolized and respirable release fractions. It is not difficult to envision scenarios which could release either more or less plutonium oxide. For example for emergency planning the AWE (U.K.) employs source terms of $0.6 \%$ respirable and $20 \%$ aerosolized, both based upon the total amount of Pu oxidized, which are based upon accident scenarios where molten Pu droplets are formed and burned in air. As stated previously, the amount of aerosolization should depend upon mechanical effects and velocities in the fire, and both of these depend upon the particular accident scenario. In fact, Ray Carter (AWE, personal communication, December, 1991) believes the Vixen experiments to be "... a modest underrepresentation of reality...".

Therefore, my expected value for $\mathrm{Pu}$ aerosolized in a relatively quiescent fuel fire is $1 \%$ of the Pu oxidized.

Laboratory tests through 1981 are critically reviewed in detail by Stewart. $17 \mathrm{He}$ points out that the median value for aerosolization is $0.05 \%$, of which about $50 \%$ is respirable. The value for the $90 \%$ level is $0.5 \%$, and for the $10 \%$ level is $0.005 \%$. Taylor and Eidson ${ }^{18}$ in analyzing the same or similar information came to about the 
same conclusions. However, Stewart 17 and Carter (personal communication, 1991), point out that elementary laboratory scale experiments are not necessarily representative of actual fire experiments.

Much of the laboratory experimentation is described in references 17-23. An extensive compilation is given in Mishima. ${ }^{23}$ As discussed by Stewart, release fractions for many of these experiments are very low. However; Mishima's ${ }^{20}$ work is of particular interest due to the large plutonium pieces ignited and burned, ranging from 570 to $1770 \mathrm{~g}$. His release fractions, of which all were respirable, were $0.049 \%$ for run \#1 ( $570 \mathrm{~g}$ alpha-Pu), $0.014 \%$ for run $\# 2$ ( $1770 \mathrm{~g}$ hi-purity alpha-Pu), and $0.0034 \%$ for run \#3 (997 $\mathrm{g}$ delta-Pu). There was very little upflow in these experiments. For this and other reasons Stewart ${ }^{17}$ suggests that the amount released would have been $0.1 \%$. On the other hand, Mishima's experiments 22 with small pieces of plutonium led to very low release fractions (again all respirable) of $3 \times 10^{-8}$ to $5 \times 1 u^{-7}$.

The more recent work of Eidson et al. ${ }^{21}$ produced respirable aerosol fractions for delta-Pu, Pu-Fe and Pu-U alloys averaging $0.21 \%$ with a worst case of $0.46 \%$.

On the basis of the Vixen $A$ tests and these laboratory thermal simulations, my recommended expected value for respirable fraction for $\mathrm{Pu}$ aerosolization in relatively quiescent fuel fires is $0.05 \%$ of the total Pu oxidized. This estimate is also consistent with Ballereau's ${ }^{24}$ recommendation of $0.05 \%$ for combustion in a kerosene fire of $1000^{\circ} \mathrm{C}$. Certainly a case can be made for other values, both higher and lower, but there appears to be considerable support for an expected respirable fraction of about $0.05 \%$ and also good evidence for an aerosolizable fraction on the order of $1 \%$, both based upon the total amount of plutonium oxidized. $A$ recommended aerodynamic particle size distribution for expected values, upper and lower bounds is shown in Table 1. It is a combination of field and laboratory experimental data.

Both Carter (personal communication, 1991) and Stewart $13,17,19$ state that in relatively quiescent burns, as in laboratory tests and in the Vixen $A$ tests, a protective $\mathrm{PuO}_{2}$ layer will form in the absence of temperature fluctuations or mechanical disruptions. But if metal surfaces are freshly exposed (as in mechanical or thermal shock) the release would be higher. It is suggested that an upper bound may be estimated for the latter cases, which might be experienced for accidents in which molten Pu droplets are formed which then fall through the fire.

Evidence for such an upper bound can be found in the experiments of Carter and Stewart 25 and of Nelson et al. 4, 6,7 The work of Carter and Stewart involved resistive heating of plutonium and uranium samples until they melted and fell through air in a $0.75 \mathrm{~m}$ column. The droplets reacted rapidly and cumulated in a "sparking," or "explosive" event. The experiments indicate respirable fractions of up to $1 \%$, with the median at about $0.4 \%$. The exothermic oxidation apparently 
produces a very vigorous reaction leading to self-heating to very high temperatures (up to $2000^{\circ} \mathrm{C}$ ) showers of sparks, the emission of vapor, condensation and aggregation as fine oxide fume. About $20 \%$ of the plutonium was aerosolized.

The work of Nelson et al. involved ignition of plutonium sample with a laser followed by free-fall in air in a $3 \mathrm{~m}$ column. The Pu droplets in these experiments were smaller than those in the Carter and Stewart experiments, (20-200 mg for Carter and Stewart, $500 \mu \mathrm{g}$ or less for Nelson et al.). From 10 to $30 \%$ of the Pu was aerosolized in respirable fractions for Pu droplets of $200 \mu \mathrm{m}$ and $400 \mu \mathrm{m}$, respectively. "Explosive" events were also observed. Similar results were also obtained for molten uranium droplets in a high speed gas flame by Benson and Rader. ${ }^{9}$

Based upon data for oxidation of molten Pu metal droplets, my estimate for the upper bound of amount of $P u$ oxide released as a respirable fraction in a fuel fire is $0.5 \%$. It is consistent with Eidson et al.'s "worst case," consistent with the U.K. emergency response planning value of $0.6 \%$, and lower than the up to $30 \%$ values based on scenarios of high temperature combustion of liquid metal droplets. Note that Ballereau also recommends a respirable fraction of $1 \%$ for reaction at 1500 $2000^{\circ} \mathrm{C}$.

My estimate for the corresponding upper bound of the amount of Pu oxide aerosolized in a fuel fire is $10 \%$, which is lower than that observed in many of the molten droplet experiments.

A lower bound estimate is somewhat arbitrary, as it depends, as I stated previously, upon accident scenarios, but a reasonable lower bound for respirable fraction of $\mathbf{P u}$ released from fuel fires is estimated to be $0.005 \%$, which is at the $10 \%$ lower bound for release fractions for all experiments (Stewart 17). It is also consistent with the minimum value estimated by Stewart ${ }^{13}$ for the Vixen tests of $0.0035 \%$. A somewhat arbitrary estimate for a lower bound of the total aerosolized is $0.1 \%$. In all cases, my estimates are based upon the amount of plutonium oxidized.

Some accident scenarios defined by the DOE Pilot Study involved some plutonium hydride. I am not at all knowledgeable of plutonium hydride technology. The source term work of Haschke ${ }^{16}$ appears to be appropriate for the hydride portion of these accident scenarios. 


\section{REFERENCES}

1. B. A. Boughton, L. E. Edwards, L. W. Hantel, J. M. Haschke, J. R. Humphrey, R. E. Luna, D. R. Stephens, R W. Mensing, T. R. Bement, "Characterization of Plutonium Aerosols for Various Accident Scenarios by an Expert Panel," Los Alamos National Laboratory Rept. LA-CP-95-55 (March 29, 1995).

2. D. F. McVey and R. E. Luna, "Some Comments on the Response of Nuclear Weapons Exposed to Hydrocarbon Fuel Fires," Rept. SC-DR-70-811 (Dec. 1970).

3. R. E. Luna, H. W. Church, and J. D. Shreve, Jr., "Variability of Air Sampler Data," Atmospheric Environment, 5, 579 (1971).

4. L. S. Nelson, N. L. Richardson, O. G. Raabe and S. V. Teague, "PAGE Program Summary Report: Aerosolization and Related Phenomena that Occur During Plutonium and Uranium Droplet Combustion," part I, Sandia National Laboratories, Report No. SAND 75-0603 (July, 1976).

5. R. E. Luna, H. W. Church, R. M. Elrick, D. R. Parker, L. S. Nelson, and O. G. Raabe, "Combustion and Smoke Formation Following Exposure at Actinide Metals to Explosions," Rept. SAND 75-6246 (1975).

6. O. G. Raabe, S. Y. Teague, L. S. Nelson, N. L. Richardson 'PAGE Program Summary Report. Aerosolization and Related Phenomena that Occur During Plutonium and Uranium Droplet Combustion," Rept. SAND 79-0556 (April 1981).

7. O. G. Raabe, S. Y. Teague, N. L. Richardson and L. S. Nelson, "Aerodynamic and Dissolution Behavior of Fume Aerosols Produced during the Combustion of Laser-Ignited Plutonium Droplets in Air," Health Physics 35, pp. 663 - 664 (1978).

8. B. A. Boughton, 'Prediction of Radiological Dispersal From Sabotage Incidents Involving High Explosives," INMM Conference (1986).

9. D. A. Benson and D. J. Rader, "Electromagnetic Launcher Studies in Breakup and Aerosol Formation in Molten Uranium Alloy," Rept. SAND 90-0021 (March 1990).

10. R. E. Luna and W. F. Hartman, "Recommended Procedure for SNL Dispersal Predictions," SNL, A report to distribution (August 9, 1990).

11. Bruce Goodwin, personal communication (1993). 
12. Douglas B. Clarke, "RADCON One-Point Detonation and Disassembly Calculations (CU)," LLNL Rept. CD-92-0197 (June 30, 1992), SRD.

13. K. Stewart, "Vixen A Trials, Experiments to Study the Release of Particulate Material During the Combustion of Plutonium, Uranium and Beryllium in a Petrol Fire," AWRE Rept. No. T15/60 (1959).

14. R. F. Carter, "Plutonium Accountability for Rounds 13 and 14 of Vixen A 1959," Rept. SDTN No. 9/86, AWRE, UK (June 1986) UK Restricted.

15. Robert E. Luna, "A New Analysis of the Vixen A Trials," Rept. SAND93-2528, Sandia National Laboratories (February, 1994).

16. John M. Haschke, "Evaluation of Source-Term Data for Plutonium Aerosolization," Los Alamos National Laboratory Formal Report LA-123315-MS (1992).

17. K. Stewart, "On the Dispersal of Plutonium by Fires," Rept. SDTN No. 1/81, AWRE, UK (April, 1981).

18. M. Taylor and A. F. Eidson, "Comparison of Current Plutonium Combustion Studies with the Existing Data Base (U)", Sandia National Laboratories, Rept. No. SAND 85-0810 (January, 1986) CRD.

19. K. Stewart, "The Particulate Material Formed by the Oxidation of Plutonium," Progress in Nuclear Energy, Series IV, Technology, Engineering and Safety, Vol. 5, pp. 535-579 (1963).

20. J. Mishima, "Plutonium Release Studies II. Release From Ignited, Bulk Metallic Pieces," Batelle Memorial Institute, Pacific Northwest Laboratories, BNWL-357 (November 10, 1996).

21. A. F. Eidson, H. C. Yeh and G. M. Kanapilly, "Plutonium Aerosol Generation in Reducing and Oxidizing Atmospheres at High Temperatures," J. Nucl. Mat., 152, pp. 41-52 (1988).

22. J. Mishima, "Plutonium Release Studies - I: Release from the Ignition of Metal," Batelle Memorial Institute, Pacific Northwest Laboratories, BNWL-205 (1965).

23. J. Mishima, "Recommended Values and Technical Bases for Airborne Release Fractions (ARFs), Airborne Release Rates (ARRs), and Respirable Fractions (RFs) at DOE Non-Reactor Nuclear Facilities," Revision 2, DOE-STD-0013093 (July 1993) draft.

24. Pierre Ballereau, "Formation of Aerosols by Oxidation and Combustion of Plutonium and Its Compounds," translated from original title "Formation 
d'aerosols par oxydation et combustion du plutonium et se; composes,"

Commissariat A L'Energie Atomique, Bibliographic CEA-B!B-242 (1987) UCRLTT-108790.

25. R. F. Carter and K. Stewart, "On the Oxide Fume Formed by the Combustion of Plutonium and Uranium," Inhaled Particles 3, Proc. Int. Symp. 3rd 1970 (Pub. 1971), 2, pp. 819-838. 
Table 1.

Aerosol size distribution for plutonium oxide resulting from fuel fires. Composite of several field and laboratory experiments. Particles are expressed as aerodynamic diameters, or equivalent spherical particles of unit density (1.0 $\mathrm{g} / \mathrm{cm}^{3}$ ).

\begin{tabular}{|c|c|}
\hline Aerodynamic diameter, $\mu \mathrm{m}$ & \% less than \\
\hline 0.1 & 0.03 \\
\hline 1.0 & 0.7 \\
\hline 10 & 5.0 \\
\hline 100 & 66 \\
\hline 1000 & 98 \\
\hline
\end{tabular}




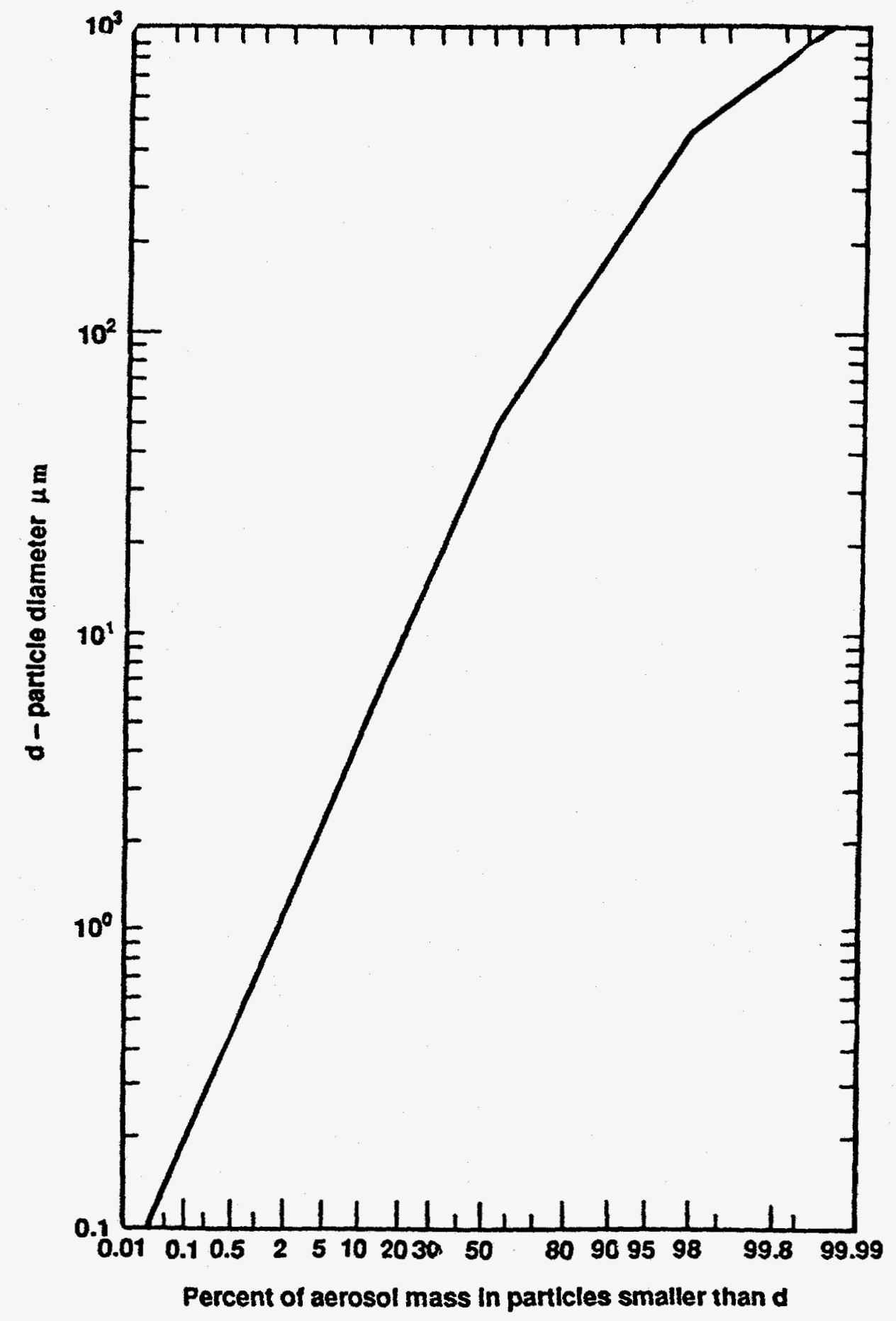

Figure1. Aerosol size distribution for roller coaster experiments 